Интернет-журнал «Науковедение» ISSN 2223-5167 http://naukovedenie.ru/

Выпуск 6 (25) 2014 ноябрь - декабрь http://naukovedenie.ru/index.php?p=issue-6-14

URL статьи: http://naukovedenie.ru/PDF/195PVN614.pdf

DOI: 10.15862/195PVN614 (http://dx.doi.org/10.15862/195PVN614)

УДК 33

Федотова Ольга Дмитриевна

ФГАОУ ВО «Южный федеральный университет»

Россия, Ростов-на-Дону 1

Зав. кафедрой психологии и педагогики высшего образования

Доктор педагогических наук, профессор

E-mail: fod1953@yandex.ru

\title{
Структуралистская педагогика ФРГ: истоки, предпосылки, гносеологические источники
}

1 344000, .г. Ростов-на-Дону, Б. Садовая, 105/42, 
Аннотация. Статья посвящена проблеме дифференциации педагогического знания, которая связана с поиском классификационных основ ее новых ветвей, отраслей и направлений. На примере педагогики Федеративной Республики Германии, теория которой формировалась под влиянием разнонаправленных научных, идейных и теоретических тенденций, автор рассматривает особенности становления и развития одного из вариантов ее неокантианской концептуализаций - структуралистской педагогики. Рассматриваются идейные и теоретические предпосылки, определившие развитие структуралистской педагогики преодоление психологизма и элементаризма, связанное с переходом от множественной элементарности к ее изучению в рамках схемы, отражающей идею функционального единства; идеи Вюрцбургской школы и гештальтпедагогики. Показано, что в структуралистской педагогике предметом научного исследования выступают взаимосвязи, законы, правила, характеризующие отношения между элементами действительности или их мысленными конструктами. Выявлено соотношение диахронического и синхронического подхода и установлено, что в основу понимания развития в структуралистской педагогике положены логические операции мысленного преобразования единого абстрактного инварианта. Тематически структуралистская педагогика охватывает самые широкие аспекты педагогической проблематики - от утилитарно-дидактической до трансцедентальнопознавательной, выходящей за сферу наличного бытия лиц, непосредственно участвующих в образовательном процессе.

Ключевые слова: образование; педагогика; немецкая педагогика; неокантианство; гербартианство; структурализм; структуралистская педагогика; гештальтпедагогика.

Ссылка для цитирования этой статьи:

Федотова О.Д. Структуралистская педагогика ФРГ: истоки, предпосылки, гносеологические источники // Интернет-журнал «НАУКОВЕДЕНИЕ» 2014. № 6 http://naukovedenie.ru/PDF/195PVN614.pdf (доступ свободный). Загл. с экрана. Яз. рус., англ. DOI: 10.15862/195PVN614 
Вхождение Российской Федерации в систему всемирных связей в области образования и науки явилось знаменательным этапам развития отечественной педагогики, актуализировавшей интерес к зарубежным педагогическим проблемам методологического характера [1]. Углубляющийся процесс дифференциации современного педагогического знания порождает сложную и многоаспектную классификационную проблему [2, 3]. Современные научные подходы к созданию типологий и классификаций различны. Они могут быть рассмотрены на примере педагогики ФРГ как страны, которая в силу наличия глубоких философских традиций располагает достаточно широким спектром методологических подходов к решению теоретических проблем методологического характера. При этом педагогика в ФРГ, не имея самостоятельного научного статуса, является прикладной философской дисциплиной, концентрирующей свое внимание не на фундаментальных проблемах «Что такое человек? Как он познает мир», а на их прикладном аспекте - «Как помочь человеку познать мир и себя самого, найти свое место в жизни». Современная педагогика ФРГ имеет ряд концептуализаций, построенных и наименованных по разным критериальным основаниям. На ход предметного самоопределения немецкой педагогики оказали значительное влияние традиции неокантианства, в рамках которого теоретически оформились концептуализации, осмысливающие свою проблематику в логике и категориях метода познания, такие как сравнительная педагогика [4], феноменологическая педагогика [5], инструменталистская педагогика [6], структуралистская педагогика [7].

Становление теоретических основ структурализма как в методологии науки, так и структуралистской педагогики, тесно вязано с общей тенденцией развития гуманитарного знания - перехода от эмпирически-описательного к абстрактно-теоретическому уровню исследования. Исследователи связывают появление данного направления в начале XX века с разработкой проблем лингвистики, литературоведения, искусствоведения. Отмечается специфическая особенность структурализма: «это не философия профессиональных философов и методологов» [8, с. 53]. Лидерами структурализма считаются этнолог К. ЛевиСтросс, историк культуры М. Фуко, литературовед Р. Барт, психолог Ж. Лакан. Вышеприведенный перечень исходных гуманитарных дисциплин может поставить под сомнение рассмотрение структурализма вообще и структуралистской педагогики, в частности, в рамках сциентизма. Данный момент представляется важным и нуждается в особом пояснении.

В начале XX века созрели предпосылки критического пересмотра давней традиции, согласно которой внутреннее, субъективное переживание признавалось единственно верным путем постижения истины. В противовес субъективности в познании выдвигается требование объективного и беспристрастного изучения процессов и явлений: индивидуальному иррациональному постижению противопоставляется стремление к логической стройности и критериальной универсальности, стихийности познавательного акта - его понимание в категориях закономерности и устойчивости. Данные подходы не являлись чем-то принципиально новым в сложившихся к тому времени рационалистических теориях познания, однако они использовались лишь применительно к анализу естественнонаучного и точного знания. Перенос вышеназванных требований в область гуманитарных наук, содержание которых считалось ранее неподвластным объективному рассмотрению, принес неожиданные результаты, открыв возможность нахождения базисных, устойчивых, универсальных совокупностей связей, характеризующих инвариантные свойства изучаемых гуманитариями объектов. Эти связи фиксируются понятием «структура», ранее уже известным, но применявшимся для характеристики расположения выявленных путем анализа (расчленения) частей целого. Открытие в гуманитарных науках универсального «кода», «формулы», «исчисления», лежащих в основе представлявшихся ранее хаотическим нагромождением предметных знаний, вызвало энтузиазм и эйфорию. Они базировались на иллюзии нахождения 
нового универсального методологического ключа к освоению объективных закономерностей человеческого познания и научного исследования [9], достоверность результатов которого могла бы быть проверена математически и формализована. Отсюда следовал вывод о высокой степени научной самообоснованности структуралистских позиций, их очищенности от идеологических наслоений и псевдонаучной проблематики. Таким образом, вследствие того, что содержание гуманитарных знаний явилось и остается лишь исходной базой, «субстратом» для формулирования представляющейся строгой теории, структуралистские построения должны рассматриваться в рамках сциентистского умонастроения.

Помимо тенденции повышения уровня методологической рефлексии гуманитарных наук, существенное воздействие на развитие структуралистских концепций знания оказала и современная идеологическая ситуация на западе, для которой было характерно подспудное ощущение дегуманизации и отчуждения человека всеми слоями населения, особенно интеллигенцией. Возникает неудовлетворенность уровнем теоретического осмысления проблемы бытия человека в мире, которое основывалось на индивидуализме, субъективизме и антропоцентризме. Ощущение усиления воздействия на человека не зависящих от него факторов, влияние которых не укладывалось более в устоявшиеся мыслительные схемы, требовало подведения их к какому-то новому знаменателю. Становится все более явной «необходимость воссоединить эти вновь обнаруживающиеся параметры в новое единство, понять их взаимосвязь» [10, с. 29].

Родиной структурализма отечественными исследователями называется Франция, в которой пик разработки разнообразнейшей структуралистской проблематики приходится на шестидесятые годы - время кульминации леворадикальных умонастроений и выступлений. Не отрицая того факта, что комплекс научных идей, связанных со становлением и применением структурного метода получил во Франции самое широкое распространение, отметим, что задолго до теоретического оформления французского структурализма немецкая философская и педагогическая мысль обращалась к данной проблематике и разрабатывала ее с оригинальных методологических позиций. Они отражены в теоретических подходах И.Г. Гербарта, в работах Х. Эренфельса, Г. Вертхеймера.

В педагогике И.Г. Гербарта развивается идущая от Мейстера Экхарта идея функциональной зависимости изоморфных объектов, в которую привносится мысль об их эмоциональном взаимодействии. В системе воззрений мыслителя доминирующая роль отводится прообразу в большей степени, чем в исходной позиции М. Экхарта, сделавшего предметом своего рассмотрения активность модели. Однако в педагогике И.Г. Гербарта устанавливается и линия обратной связи между моделью и прообразом, позволяющая изменять систему отношений между ними на основе признания специфики духовного мира каждого компонента изоморфной системы и их способности к самоструктурированию. В построении основ педагогической теории мыслителя ведущую роль играет импликативный вывод, позволяющий установить функциональную зависимость элементов рассматриваемой структуры.

В рамках рационалистической традиции Германии, в ключе которой развивались представления И.Г. Гербарта, происходит постепенное смещение акцента в понимании предмета научной теории. Берущее начало в античности и сохранявшееся в немецкой философии представление о мире как совокупности «вещей» (объектов, тел, процессов, явлений), а «вещей» - как совокупности их свойств, принимает категориальные формы. Из свойств «вещей» выделяется как сущность ее структура, понимаемая как «внутренняя форма». Суть «вещи» отыскивается путем анализа ее составляющих: целостность разлагается сначала на компоненты, а затем - на элементы, которые находятся, как правило, на грани возможности их чувственного восприятия как доказательства их реальности. Элементаризм, нашедший концентрированное выражение в работах ведущих мыслителей того времени, выступает в 
качестве основного методологического средства науки и является основным способом рационализации действительности. Однако в начале XX века элементаризм как логикометодологическая схема подвергается сомнению. Смещается акцент с изучения содержания элемента как частицы мира на его «компонентное единство», «встроенность» в другое, более сложное организационное целое, на анализ самодвижения элементов в рамках этого нового целого и познание особенностей его внутренних форм. Возникшие на данном фоне концептуальные подходы, отражающие традиции неокантианства, дают иную трактовку отношений бытия и познания, форм мышления и представляющих их языковых структур. Они в явной или неявной форме предопределили направленность методологической рефлексии перехода от анализа множественной элементарности к ее изучению в рамках схемы, отражающей идею функционального единства. Данные позиции составили фундамент переосмысления многих позиций педагогической науки и явились исходными для оформляющейся структуралистской педагогики.

Особенно четко и аргументировано недостаточность элементаристского подхода представлена в работах Х. Эренфельса о не сводимости целого к сумме составляющих его частей. Установленные данным исследователем закономерности, обозначенные им термином «гештальткачество» (От нем. «die Gestalt» - целостная форма, облик, конфигурация, образ), характеризовали возможность сохранности целостности при полном изменении всех частей исходного целого и вероятность потери целостности при сохранении всех составляющих элементов. Исследования Х. Эренфельса послужили толчком к изучению самостоятельной роли структур восприятия и были положены в основу разработки теории гештальтпсихологии и гештальпедагогики.

Основатель данных направлений в науке Г. Вертхеймер († 1934) в своих исследованиях показал, что духовные образования имеют целостный и упорядоченный характер. Гештальты, характеризующиеся высоким динамизмом, стремятся сохранять под действие внутренних сил предельно достижимое равновесие и упорядоченность, приобретая новые качества осмысленность и прегнантность . Структуралистской педагогикой была усвоена мысль о том, что прежде всего следует определить, какие стойкие функциональные образования присущи человеку или явлению как целостности, а также воспринято понятие целого как единства, свойства которого не выводимы из свойств его частей, что в дальнейшем окажет влияние на определение предмета исследования.

На становление педагогической теории немецкого структурализма оказали существенное влияние идеи Вюрцвургской школы, основатель которой О. Кюльпе (1862-1915) в опровержение сенсуализма Э. Маха и Р. Авенариуса экспериментально доказал несводимость мышления к рекомбинации чувственных представлений [11]. Структуралистской педагогикой была воспринята нацеленность представителей данного направления на анализ неких логически постулируемых субстанций как сущностей, лежащих за пределами непосредственного переживания - идей, смыслов, отношений, идеальных конструкций.

Итак, задолго до теоретического оформления идей французского структурализма в немецкой философской, психологической и педагогической мысли была сформулирована совокупность воззрений, составивших основу для разработки нового направления современной педагогической теории. Они представлены как в виде общего умонастроения, задающего вектор рассмотрения педагогической проблематики, так и нашли отражение в форме конкретных посылок, объективированных в понятиях изоморфизма, самоструктурирования, взаимосвязи, управления, образования, прегнантности, гештальта, целостности, формы. Таким образом, в истории немецкой научной мысли были созданы предпосылки развития комплекса педагогический идей, связанных с применением структурного метода. 
Можно выделить общие концептуально важные позиции, характеризующие теоретикометодологические основы современной структуралистской педагогики ФРГ.

1. П Предметом подлинно научного исследования выступают не явленные сознанию конкретные факты, процессы, состояния, а взаимосвязи, законы, правила, характеризующие отношения между элементами действительности или мысленными конструктами;

2. Должен иметь место примат синхронического подхода над диахроническим, т.е. необходимо соблюдать требование преимущественного изучения наличного состояния структур для последующей реконструкции их истории;

3. В основу понимания развития должно быть положено не диалектическое противоречие, а логические операции мысленного преобразования единого абстрактного инварианта.

4. Результаты исследования представляются в максимально концентрированном виде - в виде формулы, закона, правила и т.п., несущих смысл функции.

Данные тезисы не исчерпывают всего многообразия подходов и позиций к характеристике исключительно многоаспектной и эклектичной структуралистской педагогики, но позволяют наметить контуры рассмотрения ее проблематики.

Гносеологическими источниками структуралистской педагогики являются сформулированные в вышеприведенных концепциях представления, в целом отрицающие и возможность, и потребность в воспроизведении в познавательном процессе свойств и качеств наличных элементов действительности. Согласно данным позициям, объективная реальность является неисчерпаемой данностью, полное и адекватное отображение которой невозможно в силу огромного количества ее разноуровневых и противоречивых характеристик. Последние не подлежат полному освоению в силу ограниченности физиологической организации человека, которому недоступно проникновение в конкретные факторы жизненного процесса. Поэтому в процессе познания должны быть воспроизведены не все наличные элементы мира, а лишь соотнесенные с задачами исследования или теми точками зрения, которыми руководствуется человек в конкретном акте познания окружающей действительности. Как составляющие исходных позиций, так и выводные тезисы или новообразования должны быть впоследствии закреплены в специальных терминах, знаках или понятиях с целью исключения неоднозначной трактовки их содержания.

Таким образом, важнейшим в исследовании, построенном на основе основоположений структуралистской педагогики, является не признание единства отражательной, преобразовательной и «воспроизводящей» мир сторон познавательного процесса, в котором объективному содержанию принадлежит определяющая роль, а момент отбора компонентов этого содержания как основы последующего конструирования его взаимосвязей и выявления функциональных зависимостей.

Осмысливая подходы к решению своих проблем в терминах структурализма, сторонники данного направления развития педагогической мысли с разной степенью осознанности опираются на операции структурного метода при исследовании своей проблематики.

Современная структуралистская педагогика ФРГ представлена не неким целостным и логически завершенным теоретическим образованием, а совокупностью изложений в разной степени глубоко разработанных предметных содержаний. Тематически охватывает самые широкие аспекты педагогической проблематики - от утилитарно-дидактической до трансцедентально-познавательной, выходящей за сферу наличного бытия лиц, непосредственно участвующих в образовательном процессе. 


\section{ЛИТЕРАТУРА}

1. Федотова О.Д., Окунева И.А. Российское образование в системе трансграничных связей // Известия Южного федерального университета. Педагогические науки, 2010. № 9. С. 15-20.

2. Федотова О.Д. Классификационная проблема в современной педагоги-ке ФРГ. // Северо-Кавказский психологический вестник, 2008. Т. 6. № 4. С. 68-72.

3. Федотова О.Д., Еровенко В.Н. Классификационная проблема в современной педагогике // Вестник Томского государственного университета. 2007. № 302. С. 208-210.

4. Федотова О.Д., Чигишева О.П. Теоретико-методологические основы сравнительной педагогики ФРГ. М-во образования и науки Российской Федерации, Акад. повышения квалификации и переподгот. работников образования. Москва, 2008.

5. Федотова О.Д. Немецкая феноменологическая педагогика // Педагоги-ка, 2006. № 3. С. 21-29.

6. Федотова О.Д., Дубовер Д.А., Парастатова В.В. Педагогические проекции инструментализма в современной школе ФРГ // Российский психологический журнал, 2011. Т. 8. № 4. С. 24-35.

7. Федотова О.Д. Теоретико-методологические основы педагогики Германии и ФРГ (конец XIX века - 90-е гг. XX века). Диссертация на соискание ученой степени доктора педагогических наук / Москва, 1998.

8. Грецкий М.Н. Структурализм: основная проблема и уровни их решения (критический очерк) // Философские науки, 1974. № 4 С. 53-64.

9. Быкасова Л.В., Федотова О.Д. Потенциалцентрированный подход в педагогике // Известия Южного федерального университета. Педагогические науки, 2009. № 7. C. 22 .

10. Автономова Н.С. Философские проблемы структурного анализа в гуманитарных науках. М.: Наука, 1977. - 271 с.

11. Kuelpe, O. Vorlesungen ueber Psychology. Leipzig, 1922.

Рецензент: Сафонцев Сергей Александрович, доктор педагогических наук, профессор, кафедра образования и педагогических наук Академии повышения квалификации Южного федерального университета. 


\title{
Fedotova Olga Dmitrievna
}

Southern Federal University

Russia, Rostov on Don

E-mail: fod1953@yandex.ru

\section{Structural pedagogy of Germany: sources, prerequisites, gnoseological sources}

\begin{abstract}
Article is devoted to a problem of differentiation of pedagogical knowledge which is connected with the search of classification bases of its new branches, forms and the directions. On the example of pedagogy of the Federal Republic of Germany the theory of which was formed under the influence of multidirectional scientific, ideological and theoretical tendencies, the author considers features of formation and development of one of the options its Neo-Kantian conceptualizations structural pedagogy. The ideological and theoretical prerequisites which defined the development of structural pedagogy - the overcoming of psychologism and an elementarism connected with transition from multiple simplicity to its studying within the scheme reflecting idea of functional unity are considered; ideas of Vyurtsburgsky school and gestalt pedagogy. It is shown that in structural pedagogy the interrelations, laws, rules characterizing the relations between elements of reality or their mental constructs act as a subject of scientific research. The ratio of diachronic and synchronic approach is revealed and established that logical operations of mental transformation of a uniform abstract invariant are the basis for understanding of development in structural pedagogy. Thematically structural pedagogy covers the broadest aspects of a pedagogical perspective - from utilitarian and didactic to transcendental and informative, going beyond the sphere of cash life of the persons who are directly participating in educational process.
\end{abstract}

Keywords: education; pedagogy; German pedagogy; Neo-Kantianism; gerbertianism; structuralism; structural pedagogy; gestalt pedagogy. 


\section{REFERENCES}

1. Fedotova O.D., Okuneva I.A. Rossiyskoe obrazovanie v sisteme transgranichnykh svyazey // Izvestiya Yuzhnogo federal'nogo universiteta. Pedagogicheskie nauki, 2010. № 9. S. 15-20.

2. Fedotova O.D. Klassifikatsionnaya problema v sovremennoy pedagogi-ke FRG. // Severo-Kavkazskiy psikhologicheskiy vestnik, 2008. T. 6. № 4. S. 68-72.

3. Fedotova O.D., Erovenko V.N. Klassifikatsionnaya problema v sovremennoy pedagogike // Vestnik Tomskogo gosudarstvennogo universiteta. 2007. № 302. S. 208210.

4. Fedotova O.D., Chigisheva O.P. Teoretiko-metodologicheskie osnovy sravnitel'noy pedagogiki FRG. M-vo obrazovaniya i nauki Rossiyskoy Federatsii, Akad. povysheniya kvalifikatsii i perepodgot. rabotnikov obrazovaniya. Moskva, 2008.

5. Fedotova O.D. Nemetskaya fenomenologicheskaya pedagogika // Pedagogi-ka, 2006. № 3. S. 21-29.

6. Fedotova O.D., Dubover D.A., Parastatova V.V. Pedagogicheskie proektsii instrumentalizma v sovremennoy shkole FRG // Rossiyskiy psikhologicheskiy zhurnal, 2011. T. 8. № 4. S. 24-35.

7. Fedotova O.D. Teoretiko-metodologicheskie osnovy pedagogiki Germanii i FRG (konets XIX veka - 90-e gg. KhKh veka). Dissertatsiya na soiskanie uchenoy stepeni doktora pedagogicheskikh nauk / Moskva, 1998.

8. Gretskiy M.N. Strukturalizm: osnovnaya problema i urovni ikh resheniya (kriticheskiy ocherk) // Filosofskie nauki, 1974. № 4 S. 53-64.

9. Bykasova L.V., Fedotova O.D. Potentsialtsentrirovannyy podkhod v pedagogike // Izvestiya Yuzhnogo federal'nogo universiteta. Pedagogicheskie nauki, 2009. № 7. S. 22.

10. Avtonomova N.S. Filosofskie problemy strukturnogo analiza v gumanitarnykh naukakh. M.: Nauka, 1977. - 271 s.

11. Kuelpe, O. Vorlesungen ueber Psychology. Leipzig, 1922. 